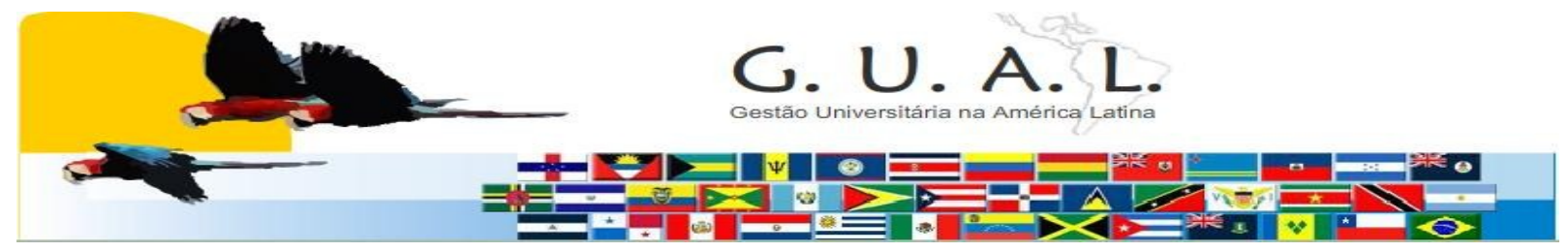

ISSN 1983-4535

\title{
A INTERIORIZAÇÃO DA EDUCAÇÃO SUPERIOR NO BRASIL: CASO DE MATO GROSSO
}

\author{
Arno Rieder, Doutor \\ Universidade do Estado de Mato Grosso - UNEMAT \\ riederarno@gmail.com
}

\section{RESUMO}

Aborda-se a interiorização e expansão da Educação Superior Pública Estadual no Mato Grosso(MT), Brasil. Em 1978 nasce o Instituto de Ensino Superior de Cáceres-IESC; estadualizado em 1985. Até 1990 atende apenas Cáceres. Depois se expande, interiorizandose para outras regiões de MT, então com o nome de Fundação de Ensino Superior de Mato Grosso (FESMAT). Em 1993 assume o nome de Universidade do Estado de Mato Grosso (UNEMAT), sendo credenciado como tal em 1999. Em Cáceres está a sede Administrativa e o Campus pioneiro. Entre 1990-2002, através de estrutura multi-Campi atende Sinop, Colider, Alta Floresta, Luciara, Nova Xavantina, Alto Araguaia, Barra do Bugres, Tangará da Serra, Pontes e Lacerda. Entre 1998-2002 implanta um processo de expansão-2 de áreas e formatos ofertados. A partir dos Campi, atende outros municípios, através de programas e turmas especiais. A UNEMAT começou do sonho de um povo sofrido, mas determinado e audaz; faz 30 anos, cuja consolidação, teve vários episódios de luta de classes, idéias e ideais, sempre, na hora certa, com respaldo de seu povo. Graças a existência da Educação Superior(ES) no interior de MT, há progressão sustentada do desenvolvimento local. É a primeira de MT, que implantou Licenciatura Plena em Computação e ES Indígena.

Palavras-chave: Educação superior. Interiorização. Expansão. Extensão. Desenvolvimento. 


\section{INTRODUÇÃO}

Este texto é um registro de uma interpretação atual de fatos vivenciados no exercício intenso da educação superior (décadas de 1970-2000), de suas transformações fortemente relacionadas com a extensão universitária e, em especial, de sua interiorização. Nesta abordagem, enfatiza-se o caso da Universidade do Estado de Mato Grosso-UNEMAT. Versões da gênese desta instituição são tratadas em Rieder (2007) e em Zattar (2008a). O processo de expansão da instituição também é analisado sociologicamente por Gianezini (2009). Desde a sua gênese (1978) até a presente década (>2000); revelam-se as estratégias utilizadas para que tivesse êxito o seu nascimento, crescimento, expansão e interiorização.

A expansão tem um sentido amplo, envolvendo desde a diversidade de opções de serviços ofertados como até de vagas ofertadas, no tempo e no espaço.

A interiorização pode ser entendida como um processo de inclusão através da democratização espacial do acesso a mesma._Medeiros (2008) estudando o caso da UNEMAT enfatiza a inclusão social promovida pela universidade diante das peculiaridades de sua experiência. Atualmente, a UNEMAT está consolidada (ZATTAR, 2008b). Trata-se de uma universidade multi-campi e multi-nucleada, democratizando e ampliando as oportunidades de acesso a mesma, e contemplando atendimentos apropriados às peculiaridades locais e regionais, alinhada nos princípios do desenvolvimento sustentado.

A gênese e a prosperidade da UNEMAT aconteceram, essencialmente, devido a um contexto demandador existente e, graças a decisão e determinação de alguns atores sonhadores e audazes na busca incessante, respaldados pela força e participação popular, nos momentos cruciais. O presente trabalho objetiva revelar o conjunto de acontecimentos, processos, ações e estratégias envolvidas para tornar realidade o sonho de o povo ter educação superior pública e estadual no interior de Mato Grosso.

\section{METODOLOGIA}

A versão dos fatos descritos e sua discussão reflexiva estão baseadas em depoimentos ("história de vida" de um sujeito ator), documentos e em referencias bibliográficos dispersos. Até então, a parte essencial desta versão, para ser expressa, estava na memória de quem a vivenciou (ator partícipe dos acontecimentos ou ator sujeito).

Perfil biográfico de vivência do ator no ambiente da Educação Superior pode ser 
qualificado como fonte adequada para a abordagem dos objetivos deste texto (anexo). A versão do ator suscitou do desejo de revelar "a história vivenciada" pelo mesmo, e de "suas próprias interpretações". Os estímulos a sua suscitação se deram de forma mais objetiva a partir de resgates de histórias de vida propostos por Motta (2007) e por Gianezini (2009). O ator redigiu sua versão dos fatos, reforçados com provas documentais quando existiam. Isto formou a base de dados, junto com a revisão bibliográfica, para o desenvolvimento do presente texto.

Assim a presente iniciativa transforma "memórias e pensamentos" em texto elaborado e escrito que, ao ser publicado tornar-se-á não mais efêmero e nem inacessível. Registra-se resgatando da história dos processos e da dinâmica transformada da educação superior, desde a década de 70, em especial, com base no que ocorreu no interior de Mato Grosso.

\section{DESENVOLVIMENTO}

\subsection{Considerações gerais}

\subsubsection{Educação superior no Brasil: modelo tradicional, localização, limitações de acesso e conseqüências}

A Educação Superior no Brasil era ofertada essencialmente nas metrópoles, capitais e em algumas cidades do interior do país. A Universidade Federal de Santa Maria (UFSM) foi a pioneira (década de 60) na interiorização do Ensino Superior no Brasil, numa época em que apenas existiam universidades nas capitais dos estados (ESTRADA, 2000). Era restrito o acesso a cursos superiores de pessoas do interior amplo deste país, tendo êxito apenas poucos privilegiados ou audazes. Isto fortalecia um modelo de desenvolvimento que acelerava o processo de concentração das populações nas capitais e metrópoles, sem, contudo criar-se condições sociais e econômicas adequadas nestes locais para tal, contribuindo, como conseqüência no acentuamento dos problemas sociais.

A elite pensante, formadora de opinião, era preparada para encontrar o seu espaço social e econômico nas Universidades. E os setores (indústria, comércio, serviços especializados) responsáveis pelo desenvolvimento da economia local, regional e nacional se beneficiavam contratando o recursos humanos preparado pelas instituições. Em geral, tais setores instalavam suas sedes próximas as Universidades. COUTO et al. (2005), entre os fatores de desenvolvimento regional, identificam a localização das Universidades. A 
Conferência Internacional sobre "Cooperação Amazônica e Educação Superior para um Desenvolvimento Humano e Sustentável" conclui que a educação superior de qualidade e a produção do conhecimento científico e tecnológico através de processos rigorosos são peças fundamentais para alcançar patamares satisfatórios de desenvolvimento (VACA et al., 2007).

Por outro lado, no interior, distantes dos grandes centros de Educação Superior, o sonho de cursar faculdade, mantinha-se reprimido em indivíduos que suscitavam mudar de condição social e que viam na Educação Superior essa possibilidade. Mas para tal tinham que migrar para às capitais, as vezes levando consigo familiares. Predominantemente estes não retornavam, depois de formado, às suas origens. Isto então também representava drenagem de talentos do interior para a capital.

Este modelo acentuava as carências do interior brasileiro e aprofundava os problemas sociais nas capitais e metrópoles. Mantinha um interior modesto e pobre, enquanto as capitais apresentavam um desenvolvimento desordenado e descontrolado.

Em 2007, numa Conferência Internacional sobre Educação Superior na Amazônia, constataram que nesta região ainda há fuga significativa de cérebros tanto para o exterior como para regiões mais desenvolvidas dos países (VACA et al., 2007).

\subsubsection{Mudanças importantes nas universidades através das ações de extensão}

A revisão da distribuição espacial da localização das Universidades tornava-se uma necessidade cada vez mais evidente. Esta percepção se acentuou no período da interiorização de ações extensionistas das universidades brasileiras experimentadas na década de 1970 e 1980, em especial através do Projeto Rondon.

Foi um período extremamente importante para re-oxigenar internamente as Universidades e suas concepções. Foi uma fase em que passaram a perceber que estavam isoladas da realidade brasileira. E constatava-se que os famosos muros da academia precisavam ser quebrados. $\mathrm{E}$ isto começou acontecer. $\mathrm{E}$ as universidades passaram também a intensificar contatos com as comunidades, seja em suas proximidades como em regiões longínquas. Nestas, principalmente, em atuações através de programas de operações do Projeto Rondon.

Conforme SEBINELLI (2004) o Fórum Nacional de Pró-Reitores de Extensão das Universidades Públicas Brasileiras conceitua a extensão na perspectiva de ocorrer a interação entre universidade-comunidade e a promoção social. Menciona que os movimentos sociais 
mundiais, na década de 60, exigiam que as universidades reconhecessem o conhecimento popular e a democratização do seu acesso. E assim a extensão teria que ser entendida como uma das três funções da universidade, formando o tripé junto com a pesquisa e ensino.

A extensão universitária é uma atividade acadêmica capaz de imprimir um novo rumo à universidade brasileira e de contribuir significativamente para a mudança da sociedade (ALVES \& ANGELO, 2008).

\subsubsection{Extensão universitária através do Projeto Rondon}

Nos anos de 1970 havia vários tipos de operações do Projeto Rondon (regionais, nacionais, especiais, campi avançados, interiorização de mão-de-obra qualificada) que envolviam professores e estudantes universitários. Os quais atuavam, dentro de projetos de sua especialidade, nas comunidades. As operações nacionais tinham além dos objetivos de interesse da comunidade, oportunizar aos acadêmicos o conhecimento de outras realidades brasileiras, distintas daquelas do entorno das universidades.

As operações nacionais duravam em torno de 1 mês, em geral implementadas no período de férias de verão. Isto também aconteceu com as Operações Campi Avançados, com a diferença que nestas haviam programas e projetos prolongados para serem executados por estudantes, mas coordenados por professores das universidades, em comunidades distantes destas. Outra característica da operação Campi Avançados foi a presença permanente das universidades nas comunidades, em forma de rodízio mensal de equipes. Isto estreitava as relações com as comunidades de atuação.

Os municípios que receberam Campi Avançados estavam intencionalmente situados distantes e/ou em outra realidade daquela em que as universidades estavam sediadas. Além disto, os municípios escolhidos apresentavam enorme carência de quase tudo, inclusive de recurso humano especializado. Então, a presença de estudantes universitários já próximos a se graduarem, era tipo uma "dádiva divina" que chegava nestes municípios e em suas comunidades. Havia, nas equipes de rodízio dos Campi Avançados presença freqüente de estudantes das áreas de educação, saúde, agrárias, engenharias, administração, direito, ação social entre outras. Os estudantes, orientados na retaguarda por professores responsáveis específicos de sua, acompanhados localmente pela equipe da direção dos Campi Avançados, eram muito bem recebidos e esperados pelas comunidades que atendiam.

Os estudantes da área de Licenciaturas atuavam nas escolas e, muitas vezes suprindo 
emergencialmente a falta crônica de professores. Os da área de saúde faziam atendimentos em postos existentes ou improvisados, orientações, palestras e campanhas de vacinações. Os da área de agrárias, além de assistência e extensão rural desenvolviam estudos/pesquisas de interesse agronômico. Os estudantes de direito se integravam nas atuações do fórum. Os de Engenharia e Administração contribuíam com as prefeituras locais. E assim por diante.

Confirmando avaliações de sua primeira fase (entre finais das décadas de 1960-80) sobre o significado e importância do Projeto Rondon, as concepções recentes de ALVES \& ANGELO (2008) mostram que a extensão universitária praticada através das Operações do Projeto Rondon continua tendo enorme impacto positivo em todas as partes envolvidas. A Universidade comunica-se com as realidades do país, induzindo-a a renovar constantemente sua própria estrutura, seus currículos e suas ações, atendendo assim melhor a verdadeira realidade do país.

Esta ação de extensão universitária, de interação entre a universidade e a comunidade, funciona como uma via de duas mãos, em que a primeira leva conhecimentos e/ou assistência à comunidade e recebe dela retroalimentação, indicando suas reais necessidades, seus anseios, aspirações, e ainda aprende com o saber dessas comunidades. Nesta troca de conhecimentos, envolvimento e reflexão todos se beneficiam, lapidando a formação daqueles que tiveram a oportunidade de participar do projeto.

Tomas (2007) menciona que a experiência vivida por alunos no Projeto Rondon Minas lhes faz constatar que o ensino e a pesquisa na academia podem ser introduzidos na sociedade através da extensão universitária. As percepções dos alunos envolvidos sobre o planejamento, a execução, e os resultados das atividades revelam-lhes, ao ser colocado em contato com realidades presentes nas demandas sociais brasileiras, efeitos positivos propiciados pela extensão acadêmica na formação humana e profissional do estudante. Acreditam que a socialização do conhecimento pode ajudar a construir de uma nova sociedade, mais includente e desenvolvendo-se socialmente.

\subsubsection{Acesso às Universidades longínquas e a esperança do retorno}

Famílias locais tentavam obter apoio da direção dos Campi para encaminhar seus filhos a estudarem em cursos universitários. Pois vislumbrava aí uma perspectiva melhor para os mesmos, e acreditavam que ao retornar formados às suas comunidades, poderiam contribuir substancialmente para elevar a qualidade de vida local. Alguns convênios com as 
Universidades responsáveis pelos Campi se concretizaram para tal. Mas mostrou-se tanto insuficiente como ineficaz, pois atendia uma pequena parcela dos que pretendiam cursar uma faculdade e, uma importante proporção, após concluir seus cursos, não retornava a sua cidade de origem.

\section{2 Educação superior no interior de Mato Grosso}

\subsubsection{Campus Avançado de Cáceres}

Em Cáceres começou a funcionar um Campus Avançado-Projeto Rondon, em julho de 1973. As Universidades responsáveis pelo mesmo eram a Federal de Pelotas (UFPel) a Católica de Pelotas (UCPel), a Federal do Mato Grosso (UFMT) e a Fundação Universidade de Rio Grande (FURG). Estudantes do sul do Brasil vinham atuar neste Campus, cujo município sede também apresentava enormes carências como já mencionadas antes. Estas atuações ajudavam muito, mas a solução vista pela comunidade era esta conseguir qualificar melhor seu próprio povo.

\subsubsection{O pleito de oferta local de cursos superiores}

Em Cáceres as famílias também constataram que o acesso de sues filhos às universidades lá onde estavam sediadas não era a solução para os desejos e necessidades municipais. Então lideranças locais, pleitearam às Universidades responsáveis pelos Campus, a oferta local de cursos. Inicialmente de qualificação de professores. Um foi oferecido pela UFMT, de Pedagogia, em formato de turma especial e modular (1975-79). Mas isto não era suficiente. O município precisava em várias áreas a qualificação de professores.

Necessitava também de outros cursos. Mas a prioridade era qualificação de professores para resolver a falta crônica dos mesmos nos educandários. Até então os alunos de escolas locais (Ensino Fundamental/1 ${ }^{\circ}$ Grau e Médio/2 $2^{\circ} \mathrm{Grau}$ ) eram atendidos em várias disciplinas, e por longo tempo, por leigos e voluntários para ministrarem disciplinas. Estes em geral com nenhuma formação para ser professor. Isto criava um nivelamento por baixo na qualidade da formação das gerações que se sucediam. Era, de fato, um problema grave para ser resolvido.

Esta situação perdurava por toda década de 1970 na região de Cáceres (MT). Diante disto o prefeito municipal de Cáceres (Sr. Ernani Martins) pediu ainda em 1977, aos reitores 
das Universidades responsáveis pelo Campus de Cáceres, para que oferecessem mais cursos para formação superior, a fim de resolver a carência local. Os reitores se comprometeram estudar a viabilidade do pleito, sendo porta-voz e intermediador destas negociações o Diretor do Campus Avançado de Cáceres.

\subsubsection{A decisão de criar um Instituto de Ensino Superior em Cáceres}

Diante da demora de respostas dos reitores para com o prefeito, este, em meados de 1978, chamou o Diretor do Campus de Cáceres ao seu Gabinete para uma reunião.

De forma bem objetiva, explicou a razão do chamado ao seu Gabinete. Dizendo que queria saber se os reitores tinham uma resposta para o seu pleito. A informação que o Diretor do Campus tinha era que ainda estavam estudando o caso. E o Prefeito, de imediato, disse: "Fala para os seus Reitores meu muito obrigado, não preciso mais deles. A Prefeitura de Cáceres irá resolver isto".

\subsubsection{Estratégias à tomada de decisões e encaminhamentos subsequentes}

A partir de então, o prefeito deu encaminhamento a formação de uma comissão para definir a questão da criação de uma instituição que ofertasse educação superior em Cáceres. Esta comissão foi composta inicialmente pelo Prof. Edival dos Reis Veira Silva - Diretor de uma Escola Técnica em Contabilidade, Contador João Porto Rodrigues- Dono de um Escritório de Contabilidade, Prof ${ }^{a}$ Miriam Benedita Menezes - Delegada Regional de Ensino, Prof. Luttgards Saavedras (e outros que participavam mais esporadicamente).

Reuniam-se após finalizar o expediente de seus afazeres, em fim de tarde, numa mesa em baixo de uma árvore ornamental chamada chuva de ouro (Cassia fistula L), no bar Socity, à beira do cais do Rio Paraguai em Cáceres (MT), enquanto no horizonte eram acompanhados por belo por de sol. Era o horário que dispunham, pois todos tinham que estar em serviço no expediente comercial, em seus respectivos órgãos/empresas.

Os primeiros rabiscos do projeto de educação superior em Cáceres aconteceram neste local, feito em papel guardanapo fornecido pelo próprio bar. Então aí foi concebida a criação do Instituto de Ensino Superior de Cáceres (IESC). Havia uma grande necessidade e determinação de se dar encaminhamento a solução do problema de falta de profissionais de formação superior, em especial a de professores. Porém quase nada havia de condições apropriadas para esta oferta, como também para formação do quadro de professores, local e 
estrutura adequada, recursos financeiros para tal, e faltava também experiência em gestão de Educação Superior.

Mas havia o problema para ser resolvido, o desejo de resolvê-lo, a determinação de fazê-lo resolvido, a solidariedade, a disposição de pessoas sensibilizadas e convictas da premência de dar encaminhamento para solução destes importantes desafios.

E apostaram que a força coletiva seria canalizada para, então sim, conseguir superar os desafios que se apresentavam para instalar e manter promissora uma instituição de educação superior em Cáceres, Mato Grosso, Brasil. Inicialmente foram criados cursos de Licenciaturas: Letras, Estudos Sociais e, em seguida Ciências.

O primeiro vestibular aconteceu em agosto de 1978, e as aulas inaugurais começaram em setembro daquele ano. E assim surgiu o embrião IESC que, em 1993 evoluiu para Universidade do Estado de Mato Grosso, conforme a Lei Estadual 030, e que pela primeira vez veio a ser credenciada como tal em abril de 1999 (CEE).

\subsubsection{Os desafios nos caminhos para continuar}

Neste meio tempo (1978-1985) enormes dificuldades financeiras e estruturais se apresentam e que ameaçam a sobrevivência do IESC. O município, com arrecadação decrescente, em função do desmembramento de novos municípios regionais, já não consegue mais dar sustentação a demanda financeira da instituição. A comunidade em geral (acadêmica e não-acadêmica) se une para promover mobilizações para arrecadar livros, por meio de gincanas acadêmicas e doações feitas pela sociedade local, tentado assim suprir a carência da biblioteca do IESC. Entre 1982-1985 se mobiliza também para sensibilizar o governo federal e os dirigentes da UFMT para conseguir a federalização do IESC.

Nesta mobilização engajam-se também clubes de serviços e afins (Rotary, Lions, Maçonarias), organizações representativas das atividades sócio-econômicas e administrativas do município (Prefeitura, Sindicatos, CDL, etc), representantes políticos locais e estaduais. Conseguem inclusive audiência com o Presidente da República do Brasil (na época Aureliano Chaves) para tratar do pleito de federalização do IESC.

\subsubsection{A estadualização do IESC, embrião da Universidade do Estado de Mato Grosso}

Mas paralelamente a este movimento, de modo sigiloso, o governador do Estado de Mato Grosso da época (Julio Campos) encomenda um projeto de estadualização do IESC, 
conseguindo sua aprovação na Assembléia Legislativa. E o IESC passa então, em 1985, a ser estadualizado com a denominação inicial de FCUC (Fundação Centro Universitário de Cáceres). Anos posteriores troca de nome para FCESC (Fundação Centro de Ensino Superior de Cáceres).

\subsubsection{Crise interna e mudança do modelo de gestão}

Em 1988 a instituição FCESC experimenta uma crise interna. Um movimento estudantil protesta, a partir de uma pauta de vários itens reivindicatórios, questionando e pressionando o gestor da época. O mesmo deixa o cargo, passando, depois, a ser ocupado por um professor eleito pela comunidade acadêmica (Prof. Carlos Alberto Reyes Maldonado).

3.2.4.4 A busca do respaldo político à sustentação institucional e a interiorização da Educação Superior no Mato Grosso

O novo dirigente da FCESC constata que a instituição precisa fortalecer seu respaldo político no âmbito estadual. Pois neste sentido estava frágil e podia vingar argumentos à sua extinção, pois a mesma estava sediada em Cáceres e atendia apenas parte da demanda de estudantes da região sudoeste de MT. Para manter-se estadual isto não conseguia dar uma estabilidade política consistente dentro da Assembléia Legislativa.

Para resolver a questão da busca de maior estabilidade e suporte político às necessidades de consolidação da FCESC, o dirigente da instituição (Prof. Maldonado) verificou que as carências e as necessidades de Cáceres por Educação Superior também eram de todo o interior do Mato Grosso. Só não da Capital e municípios vizinhos que possuíam o acesso à UFMT e outras privadas. Então convidou prefeitos dos municípios do interior do Estado e autoridades estaduais para uma grande reunião (I Seminário de Expansão do Ensino Superior no Mato Groso), apresentando as possibilidades, as condições e os limites da Instituição em estender seus serviços para outras regiões de Mato Grosso.

Nesta reunião alguns prefeitos manifestaram seu interesse e assumiram as condições propostas (tinha que entrar com alguma contrapartida, em especial oferecer as condições estruturais locais). A partir deste momento, amplia-se o suporte político estadual à Instituição, cria-se uma estrutura multicampi, e interioriza-se a Educação Superior Estadual.

Um renomado pensador da Educação brasileira, lá na década de 60, alertava sobre os riscos da expansão do Ensino Superior quando feita sem planejamento adequado, e 
recomendava que este processo, para ter êxito, deve ser tratado como empreendimento (FÁVERO, 2006).

\subsubsection{Estrutura multi-campi e o significado da interiorização da Educação Superior (Plano de expansão I)}

A interiorização veio atender uma enorme demanda reprimida local e regional oportunizando acesso ao Ensino Superior, para depois se estabelecer uma demanda de movimentação (ida-volta) diária de municípios vizinhos a fazer cursos de graduação nas sedes dos campi, para finalmente estabelecer-se uma demanda normal. Mas com o formato multicampi tornou-se necessário novamente alterar o nome institucional, que passou a denominarse FESMAT (Fundação de Ensino Superior do Mato Grosso).

Entre 1990 e 1994 implantam-se os campi de: Sinop (Lic. Letras, Pedagogia, Matemática), Alta Floresta (Lic. Biologia; e também turmas Especiais em Lic. Letras, Pedagogia, Matemática), Nova Xavantina (Lic. Biologia), Alto Araguaia (Lic. Letras), Pontes e Lacerda (Lic. Letras), Colider (Lic. Letras, Matemática, Biologia), Barra do Bugres (Lic. Biologia, Letras, Pedagogia), Luciara (Lic. Biologia, Matemática, Letras), Tangará da Serra (Administração, Ciências Contábeis, Lic. Letras) e Cáceres (Direito, Ciências Contábeis, Licenciaturas: Letras, Pedagogia, Matemática, Biologia, História, Geografia). A sede administrativa se mantém em Cáceres, tendo Campi distribuídos em distâncias de 1000 km (Alta Floresta) até $1600 \mathrm{~km}$ (Luciara).

\subsection{A criação em lei da Universidade do Estado de Mato Grosso - UNEMAT}

Agora, politicamente bem respaldada, a instituição, já com a dimensão que tinha e sonho que aspirava, sofre novamente alteração jurídica, passando a denominar-se UNEMAT (Universidade do Estado de Mato Grosso) através da Lei Complementar 030 de dezembro de 1993. O único Campus que surge de modo diferente é o de Tangará da Serra. O qual é adquirido pelo Estado de um grupo privado, e incorporado à UNEMAT.

\subsubsection{Características diferenciais da UNEMAT}

A UNEMAT passa a se diferenciar de Universidades tradicionais em vários aspectos. Em seu Estatuto constata-se a garantia do voto Universal, o que, a priori, contraria a Lei de Diretrizes e Bases de Educação Nacional (LDBen, de 2006- Lei Darci Ribeiro). Assim os 
dirigentes institucionais (Reitor, Diretores de Institutos, Chefes de Departamento, Coordenadores de Campi, etc.) são eleitos pelo voto universal da comunidade acadêmica (Professores, alunos e funcionários: cada voto é e tem o peso e de 1 voto). Isto gera a necessidade dos dirigentes de correntes diferentes, a desenvolverem habilidades extraordinárias de negociação na busca de caminhos convergentes para tomadas de decisões macro.

A instituição em parcerias com outras universidades desenvolve, além de cursos regulares, programas diferenciados de atendimento da demanda por Educação Ssuperior, contemplando e atendendo peculiaridades geográficas, econômicas, sócio-culturais (Licenciaturas Parcelas, Modulares, Módulos Temáticos, Ensino a Distância, Plenificação, Turmas Especiais fora de sede, $3^{\circ}$ Grau Indígena, etc.).

Desta forma cumpre um papel importante na aceleração do processo de qualificação de docentes da Educação Fundamental e Média das regiões atendidas pelos Campi no Mato Grosso, embora ainda houvessem municípios desatendidos completamente ou em determinadas áreas do conhecimento e formação. Conforme VACA et al.(2007), as atividades das instituições universitárias devem considerar os interesses, desafios e características regionais, onde as demandas sociais e a qualidade do ensino superior possa ser oportunidade de formação profissional, intelectual, técnica e política capaz de responder ao processo de reconhecimento da Amazônia como um lugar ocupando vários espaços regionais.

\subsubsection{Plano de Expansão II}

\subsubsection{Os contrastes de interesses entre sociedade e estado}

Na campanha para eleições de 1998, um dos candidatos constata que a sociedade espera muito mais da UNEMAT em relação do que ela vem oferecendo e, por outro lado, integrantes do governo do Estado, sinalizam que o papel da UNEMAT deve se restringir à formação de Professores, até que esta demanda (defasagem) seja suprida. Depois, uma das possibilidades, era dela ser extinta. Já em 1998, isto às vezes era expresso nas entrelinhas de falas, mas um secretário de estado expressou literalmente tal proposição.

\subsubsection{As estratégias utilizadas}

Notava-se novamente a necessidade de uma mobilização da sociedade mato-grossense

Rev. GUAL., Florianópolis, v. 4, n. 3, p.228-247, set/dez. 2011 
quanto ao futuro da UNEMAT, sob pena do interior voltar a ficar renegado.

Por um lado, a sociedade esperava mais da Universidade Estadual, e por outro, os dirigentes do Estado, sinalizavam para uma política de redução ou extinção da mesma. Estavam em jogo forças de interesses e visões contrastantes, conflitantes.

Conforme FERREIRA (2002), na década de 1990, as forças sociais das sociedades política e civil em movimento, inseridas no bojo do ensino superior, possibilitaram novos embates para as reformas e a reestruturação do ensino superior.

Refletindo sobre a questão, e conhecedor da história da UNEMAT desde a sua origem, um candidato a reitor, em seu plano de metas compromete-se em ampliar a atuação da mesma como universidade (ensino, pesquisa, extensão) tanto em localidades atendidas como também em vagas de acesso ofertadas.

\subsubsection{As limitações e alternativas para implementar o plano de expansão}

Entretanto, a Universidade não tinha condições (financeiras, estruturais, etc.) de arcar sozinha novos programas e projetos de ampliação de sua atuação. Mas através de propostas em parceria com outros organismos das sociedades locais e regionais, era possível reunir as condições mínimas iniciais para oferta, por exemplo, de novos cursos que estavam sendo demandados. Recomendações para melhorar e fortalecer a educação superior na região amazônica, através da cooperação, continua sendo indicadas, inclusive em encontros internacionais (VACA et al., 2007).

Constatou-se que através de parcerias (convênios), a soma das forças e das estruturas existentes, mesmo em comunidades carentes, é uma forma de encurtar caminhos para resolver desafios, que isoladamente, demorariam muito ou seriam proteladas ad eternum as possibilidades de solução. Embora, correntes de oposição política, pregavam que a parceria seria uma forma de iniciar a privatização da UNEMAT.

Ao ser vencedor nas eleições, a Chapa Travessia, que pregava o fortalecimento da UNEMAT através da ampliação de oferta de serviços e atendimento no interior do Estado, começou a viabilizar condições a concretização do plano. Começando por um mutirão de regularização institucional (reconhecimento de curso, credenciamento da universidade $-1^{\circ}$ credenciamento em maio de 1999, revisão e aprofundamento de normativas, etc.). 


\subsubsection{A fundamentação das proposições no plano de expansão}

Produziram-se estudos de viabilidade de cursos na nova expansão da UNEMAT. Em 1999, inicia-se a expansão no Campus de Barra do Bugres, com a implantação de 2 cursos regulares: Li.c Matemática, Processamento e Dados - mais tarde renomeado de Computação. Em 1999, o Conselho Universitário define uma comissão de estudo da expansão da UNEMAT em todo o Estado, e as estratégias a serem aplicadas.

Enquanto isto se discute com a sociedade a maturação das demandas, buscam-se referenciais de estudos anteriores, e de outras universidades nacionais (Ex.:UFPA, UFPel, UEMS, UEGo) e estrangeiras (Costa Rica:EARTH, UEA; México: Univ Monterrey; Cuba: Univ. de Havana, Univ. Pinar Del Rio) tanto para subsidiar a formatação de novos programas (Ex. : Ensino a Distância; Ciências Agro-Ambientais) como para cursos específicos e diferenciados (Ex.: Agronomia, Biologia, Eng ${ }^{\mathbf{a}}$ Florestal, Zootecnia; Computação; Enfermagem). Promovem-se exaustivas discussões em encontros específicos com especialistas e interessados nas diversas áreas (Ex. Ciências Agroambientais).

Concluídos os estudos de viabilidade, a intenção inicial era implantar a nova expansão da Universidade em todos os Campi no princípio de 2001. Mas limitações orçamentárias e perspectivas financeiras remeteram a implantação de um pacote de 23 cursos (predominantemente de bacharelados) para o segundo semestre de 2001. Entre estes está Licenciatura Plena em Computação, a primeira instituição a oferecer a formação de professores nesta área no Mato Grosso.

Esta expansão altera expressivamente o quadro de acesso subseqüente a educação superior no Estado. Já com esta expansão consolidada, análises de BITTAR (2006?) em seu projeto que estuda, no Brasil, a expansão do ensino superior noturno, sob a ótica da ampliação do acesso e democratização do mesmo menciona que as instituições públicas Federais (47\%) aumentaram as matrículas noturnas, além do índice nacional (35\%). Cita que na Região Centro-Oeste o índice mais significativo corresponde às matrículas em IES Estaduais, o que está atrelado a criação, expansão e interiorização dos campi das três universidades estaduais da Região: a Universidade do Estado de Mato Grosso (UNEMAT), a Universidade do Estado de Goiás (UEG) e a Universidade Estadual de Mato Grosso do Sul, UEMS.

Estas ofertam cursos de graduação no interior dos respectivos estados, em especial nos turnos noturnos, possibilitando pessoas que desejam estudar o acesso ao ensino superior 
público.

\subsubsection{Proposição de uma Secretaria de Estado de Ciência, Tecnologia e Educação Superior}

Em 2000 e 2001 o reitor da UNEMAT, após buscar e analisar referências (inclusive em outros países), primeiramente discute com Secretários de Estado, e depois propõem ao Governador e ao Presidente da Assembléia Legislativa a criação da Secretaria de Estado Ciência, Tecnologia e Educação Superior no Mato Grosso. Para formalizar isto, encaminha (abril de 2001) um projeto de criação desta Secretaria, que visa criar meios concretos ao estabelecimento definitivo de uma política continuada de aceleração e otimização do processo de desenvolvimento do Estado de Mato Grosso.

Esperava-se assentar, com isto, o desenvolvimento em bases sólidas, assim como nisto inserir e consolidar a UNEMAT, para ajudar a transformar a sociedade objetivando melhorar e dar sustentação a qualidade de vida do povo mato-grossense. Em 12 de dezembro de 2001, ao ser publicada no Diário Oficial do Estado, a Secretaria de Estado Ciência, Tecnologia e Educação Superior (SECITES) fica criada no Mato Grosso através da Lei Compl. 96/2001.

Isto foi um passo importante sob vários aspectos: (1) pela primeira vez a UNEMAT, passa a constar no organograma da estrutura organizacional do Estado; (2) O Estado passa a reconhecer a importância da ciência, da tecnologia e da educação superior, em suas funções; (3) A UNEMAT passa a fazer parte das estratégias de definição e execução das políticas de desenvolvimento do Estado; (4) A UNEMAT passa a ter mais uma garantia à sua consolidação e possibilidades de cumprir com o papel que tem, e sonhado pelo seu povo. Uma ratificação da importância desta tomada de decisão pode ser obtida em uma das conclusões na Conferência Internacional que tratou de Educação Superior na Amazônia, conforme VACA et al.(2007):

\footnotetext{
"Sem um sistema de educação superior, ciência e tecnologia de qualidade na região, voltado para os interesses regionais capaz de gerar conhecimento, utilizando as mais modernas tecnologias e incorporando os conhecimentos tradicionais, não existe possibilidade de se alcançar um desenvolvimento humano sustentável”.
}

\subsubsection{Educação Superior Indigena ( $3^{\circ}$ Grau Indigena)}

Outra inovação na UNEMAT é a oferta de cursos específicos para formação de 
professores índios ( $3^{\circ}$ grau indígena, pioneiro no Brasil) no Campus de Barra do Bugres, iniciado em 2001, com 180 vagas disponíveis para candidatos índios, de 35 etnias, de todo o Brasil. Detalhes desta iniciativa podem ser encontrados no site da FUNAI (2009) e da UNEMAT (2009).

\section{CONSIDERAÇÕES FINAIS}

Desta maneira a UNEMAT estava, por um lado:

(a) Dando resposta a uma demanda reiterada dos municípios do interior de Mato Grosso e, por outro;

(b) Revigorando a sustentação política da UNEMAT, diante da ameaça de a ela ser atribuída a função única de formação de professores. Continuou as licenciaturas (inclusive com acréscimo da Licenciatura em Ciências da Computação), mas incorporou o compromisso de atuar na formação de bacharelados mais demandados.

Com isto a UNEMAT vislumbra um novo momento de consolidação como Universidade Estadual, forte politicamente e audaz no atendimento da população em suas esperanças de conseguirem atingir saltos qualitativos em prazos encurtados.

Portanto, as estratégias mais poderosas para criar e desenvolver uma Instituição Pública de Educação Superior, em recantos de grande carência, é a determinação e participação popular, no exercício de sua cidadania.

As pessoas das comunidades locais, em geral, se envolviam intensamente com as causas da UNEMAT. Pois esta instituição foi construída, tijolo a tijolo, por decisão representada e participava das pessoas das comunidades beneficiadas. Daí a razão da frase: “ $A$ UNEMAT é uma Universidade do interior para o interior". Isto retrata que ela foi construída pelo cidadão do interior do Mato Grosso, para resolver as carências e demandas deste interior com relação às oportunidades de acesso a Educação Superior, como caminho para melhorar de vida no sentido amplo.

Há um pensamento predominante, no presente, que um dos caminhos mais prováveis e efetivos para se melhorar a qualidade de vida, é através da Educação Superior. Esta oportunidade foi criada para boa parte do interior de Mato Grosso, e que ninguém se atreva a subtrair esta conquista. A Lei Estadual 101(2002) se atreveu a mandar suspender vestibulares de alguns cursos oferecidos pela UNEMAT no interior de Mato Grosso, teve que ser revista um mês após sua aprovação e, assim mesmo produziu custos políticos altos aos principais 
atores envolvidos (Não eleição de um candidato a senador, em 2002, que estava certo que seria eleito; e a derrota, na época, do candidato ao governo do Estado de Mato Grosso).

Não é difícil de entender a reação da sociedade em proteger e fortalecer a UNEMAT, pois foi muita luta e difícil para implantá-la, atualmente multi-campi. Ela se constitui a esperança das famílias em encaminharem seus filhos à Educação Superior, que esta ali acessível, para alcançarem dias melhores. Por ser Estadual a sociedade está atenta e participa efetivamente das questões que são levantadas sobre ela e, reivindica continuamente melhorias.

Daí porque também ter sido frontalmente rejeitada (e com reflexos políticos negativos) uma proposta do governador atual em propor sua Federalização, pois neste caso o local das decisões e definições limitaria muito a participação das forças populares. Assim, a UNEMAT, tem como principal guardião o próprio povo do interior onde tem como função cumprir a aceleração e democratização do processo de desenvolvimento do estado (principalmente humano).

\section{REFERÊNCIAS BIBLIOGRÁFICAS}

ALVES, C.M.C.; ANGELO, A..C. D.. Cidadania e bem estar: uma experiência no projeto Rondon da UNESP em Jordão -AC. Rev. Ciênc. Ext. v.4, n.1, p.51, 2008. Disponível em: $<$ http://ojs.unesp.br/index.php/revista proex/article/view/20/9>. Acessado em: 11 jan 2009.

BITTAR, M. Ensino Noturno: acesso e democratização da Educação Superior (Projeto). Campo Grande, Fundect/UCDB, 2006. Disponível em:

$<$ http://fundect.ledes.net/index.php? $\mathrm{id}=4 \& \mathrm{acao}=15 \&$ projeto $\mathrm{id}=3175>$. Acessado em: $12 \mathrm{jan}$ 2009.

COUTO, A. P.; BRYAN, N. A. P.; MOMMA, A. M. [et. al.]. Conhecimento e Desenvolvimento Sustentável: dos problemas societais aos fundamentos multidisciplinares/ Organizadores: Couto, Newton A. P. Bryan;-Covilhã, Portugal: UBI; Campinas, SP, UNICAMP, Graf. FE, 2005. Disponível em:

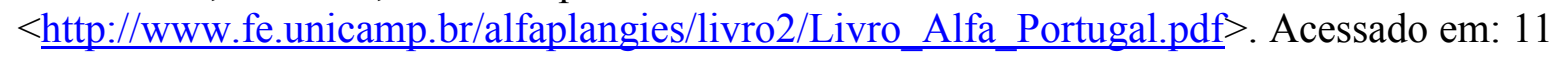
jan 2009.

ESTRADA, R. J. S.. Os rumos do planejamento estratégico na universidade pública: um estudo de caso na Universidade Federal de Santa Maria. Florianópolis, UFSC, 2000. Tese (doutorado), Universidade Federal de Santa Catarina, Centro Tecnológico, Programa de PósGraduação em Eng. de Produção. Disponível em:

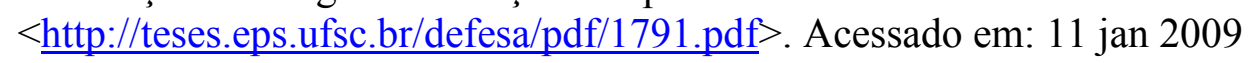

FÁVERO, M. de L. de A. Durmeval Trigueiro Mendes: idéias, propostas e atuação. Cadernos de História da Educação, $\boldsymbol{n}^{\circ} .5$, jan./dez. 2006, Uberlândia, Editora da Universidade Federal de Uberlândia, 2006. Disponível em: 
$<$ www.faced.ufu.br/nephe/arquivos/edicao5/ed5completa.pdf $>$. Acessado em: 11 jan 2009.

FERREIRA, S. Políticas de expansão e estruturação da educação superior em Goiânia nos anos 90: o caso da Faculdade Anhangüera de Ciências Humanas. Goiânia, Universidade Católica de Goiás, 2002. Dissertação (Mestrado em Educação). Disponível em:

$<$ http://tede.biblioteca.ucg.br/tde busca/arquivo.php?codArquivo=21 $>$ Acesso: 12 jan 2009 .

FUNAI - Fundação Nacional do Índio. Projeto $3^{\circ}$ Grau Indígena. Brasília, MJ, 2009(?) Disponível: $<$ http://www.funai.gov.br/projetos/3o grau/projeto 3 grau.htm $>$. Acessado em: 12 jan 2009.13

GIANEZINI, Q. O Processo de Expansão do Ensino Superior em Mato Grosso /Quelen Gianezini.- Porto Alegre, 2009. Dissertação (Mestrado em Sociologia) Universidade Federal do Rio Grande do Sul-UFRGS.

$<$ http://www.lume.ufrgs.br/bitstream/handle/10183/34038/000736137.pdf? sequence=1 $>$. Acesso em: 13 nov 2011.

MEDEIROS, I. A.. Inclusão social na universidade: experiências na UNEMAT. Dissertação de Mestrado. UNICAMP, São Paulo, 2008. Disponível em:

$<$ http://www.bibliotecadigital.unicamp.br/zeus/auth.php?back=http://www.bibliotecadigital.u nicamp.br/document $/$ code $=\mathrm{vtls} 000440488 \&$ go $=\mathrm{x} \& \operatorname{code}=\mathrm{x} \&$ unit $=\mathrm{x}>$. Acesso em: 13 nov 2011.

MOTTA, A. de M. História Oral do Projeto Rondon - entrevistas:... Arno Rieder...concedida a Estanislau Monteiro de Oliveira / Coord. Geral Aricildes de Moraes Motta. In.: História Oral do Exército - Rio de Janeiro: Biblioteca do Exército Editora, 2007. p. 317-336. 456 p. (Biblioteca do Exército; 792 . Tomo 3 - Coordenador do Projeto: Geraldo Luiz Nery da Silva).

RIEDER, A. ENTREVISTAS: Professor Arno Rieder. In: MOTTA, Aricildes de Morais (Coord. Geral). HISTÓRIA ORAL DO PROJETO RONDON. Rio de Janeiro: Biblioteca do Exército Editora, 2007. Tomo 3(Campus 9 ao Campus 23). p.317-336. 456p.

SEBINELLI, R.M. M. G. Política de Extensão Universitária: o Debate Nacional e a experiência da Universidade Estadual de Campinas. Campinas, Universidade Estadual de Campinas, 2004. Dissertação (mestrado) UNICAMP: Programa de Pós-Graduação em Educação Disponível em: <http://libdigi.unicamp.br/document/?code=vtls000320532> Acessado em: 11 jan 2009.

TOMAS, R. N. A Interação Ensino, Pesquisa e Sociedade por Meio da Extensão Universitária: uma experiência discente na partilha do conhecimento. Gestão $\boldsymbol{e}$ Conhecimento, v. 4, n. 1, art. 4, julho/ novembro 2007. Disponível em:

$<$ www.pucpcaldas.br/graduacao/administracao/nupepu/online/inicial.htm>. Acessado em: 11 jan 2009.

UNEMAT - Universidade do Estado de Mato Grosso. PROESI. Cáceres, Unemat, 2009(?). Disponível em: < http://indigena.unemat.br/index.php>. Acessado em: 12 jan 2009. 
VACA, L. E. A.; BARBA, A. T.; VALAREZO, C.; VILLAFUERTE J. E.; ACOSTA, N.; BRASIL, W. [relatores]. Conferência Internacional: Cooperação Amazônica e Educação Superior para um Desenvolvimento Humano Sustentável, Belém, Pará, Brasil, 23 a 26 de setembro de 2007. Síntese e Recomendações da conferência... Belém, 2007. Disponível em: $<$ http://www.cres2008.org/upload/documentosPublicos/docs aportes/1\%20CooperacAma zonica.pdf $>$. Acessado em 11 jan 2009.

ZATTAR, N. B. da S. Do IESC à UNEMAT: uma história plural 1978-2008/ Neuza Benedita da Silva Zattar. Cáceres[MT]: Editora Unemat, 2008. 125 p. 


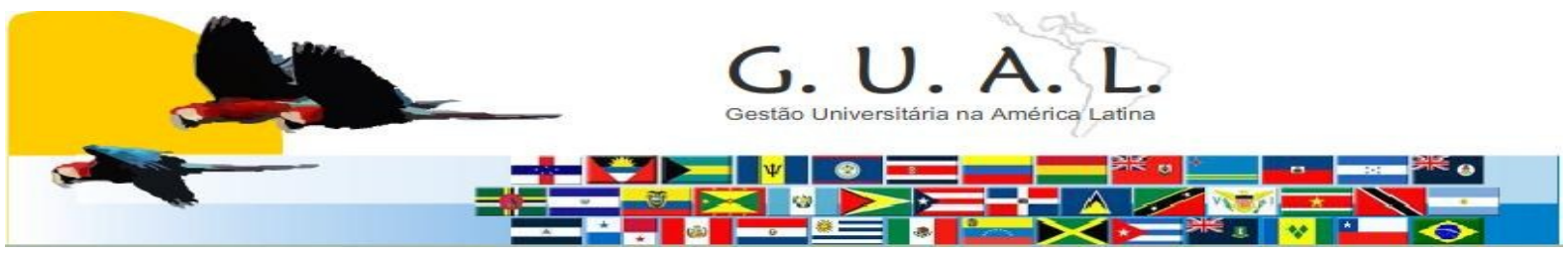

ISSN 1983-4535

\title{
THE INTERNALIZATION OF HIGHER EDUCATION IN BRAZIL: CASE OF MATO GROSSO
}

\author{
Arno Rieder, Doctor \\ Universidade do Estado de Mato Grosso - UNEMAT \\ riederarno@gmail.com
}

\begin{abstract}
We analyze the internalization and expansion of the Public Higher Education in Mato Grosso(MT) state. Brazil. Born in 1978 the Cáceres Institute of Higher Education-IESC; taken over by the state in 1985. Until 1990 only serves Caceres. After, expanding and internalizing to other regions of MT, but with a different name: Mato Grosso Higher Education Foundation(FESMAT). In 1993 definitely changed the name to University of Mato Grosso state(UNEMAT) and accredited in 1999. Cáceres held the Rectory and pioneer Campus. Between 1990-2002, through a multi-campi, serves several municipalities progressively: Sinop, Colider, Alta Floresta, Luciara, Nova Xavantina, Alto Araguaia, Barra do Bugres, Tangara da Serra, Pontes e Lacerda. Between 1998-2002 de $2^{\text {nd }}$ expansion process occurs (especially in areas and formats offered). From the Campi, serves other municipalities, through programs and special classes. The UNEMAT began the dream of a suffering people, but determined and courageous; for more than 30 years, whose consolidation had to have several episodes of class struggle, ideas and ideals, always at the right time, with your support people. Thanks to the existence of Higher Education(ES) within MT, there is progression sustained local development. UNEMAT is the first of MT, which implemented Full Degree in Computing and Indigenous ES.
\end{abstract}

Keywords: Higher education. Internalization. Expansion. Extension. Development. 